\title{
SINGLE MINUTES EXCHANGE OF DIE (SMED) APPLICATIONS AT THE COLOR CHANGEOVER PROCESS OF PLASTIC BOTTLES
}

\author{
DOI: 10.17261/Pressacademia.2018.887 \\ PAP- V.7-2018(40)-p.233-236
}

Buse Otur ${ }^{1}$, Ilgi Sila Yildirim², Mustafa Batuhan Ayhan ${ }^{3}$

${ }^{1}$ Marmara University, M.U. Goztepe Campus 34722 Kadıkoy, Istanbul, Turkey. buseotur6@gmail.com.tr, ORCID: 0000-0002-7492-0147

${ }^{2}$ Marmara University, M.U. Goztepe Campus 34722 Kadıkoy, Istanbul, Turkey. ilgissila@gmail.com.tr, ORCID: 0000-0002-3426-7243

${ }^{3}$ Marmara University, M.U. Goztepe Campus 34722 Kadıkoy, Istanbul, Turkey.

batuhan.ayhan@marmara.edu.tr, ORCID: 0000-0001-6114-7629

\section{To cite this document}

Otur, B., Yildirim, I. S., Ayhan, M. B. (2018). Single minutes exchange of die (smed) applications at the color changeover process of plastic bottles. PressAcademia Procedia (PAP), V.7, p.233-236.

Permemant link to this document: http://doi.org/10.17261/Pressacademia.2018.887

Copyright: Published by PressAcademia and limited licenced re-use rights only.

\section{ABSTRACT}

Purpose- This project's goal is to minimize total time of the color changeover process for plastic bottle's production at one of the leader companies in cosmetic sector.

Methodology- Single Minute Exchange of Die (SMED) approach is used for improving the color changeover process. Based on this analysis; variants of the colors, detailed steps of the process, time of the steps and cycle time are observed and recorded.

Findings- It was obtained that this process lasts from 2 hours to 8 hours depending on colors. This process is done at least two times in a week and it causes the production line to stop frequently. To use time efficiently and minimize work in process inventory, SMED is required and applied to decrease the time for color change over process. By applying proposed solution suggestions, time can decrease $60 \%$ for the color change over process which takes more than 5 hours. In addition, by applying other approach, the time can decrease $20.5 \%$ for any of the color change over processes

Conclusion- Color changeover process is analyzed and found out to be inefficient based on the time studies performed. By applying SMED, this process is improved by both increasing efficiency and minimizing work in process inventory.

Keywords: Single Minute Exchange of Die method, production of plastic bottles, changeover process.

JEL Codes: D24, L66, M11

\section{INTRODUCTION}

In order to survive in today's highly competitive environment, businesses must be flexible and able to respond quickly to their customers. Color changeover and set-up times, which are tiring, adding no value to the product and leading to waste of time in production are the biggest problem of a production system.

It has been worked on the process which is more laborious for the factory and which will lead a significant difference when it is solved. This factory produces shampoos and hair creams, plastic bottles in different sizes and colors. Changing color of the bottles is a process which can last at least 2 hours up to 8 hours and which is done at least twice a week. This means that the related machine will not work almost half a shift during a day. Being able to respond quickly to customer demand is quite important in terms of businesses.

By applying Single Minute Exchange of Dies (SMED) method, businesses decrease set-up times, as well as die changeover times, and they increase their responsiveness to the customer. With the approach of "time is money" in production, SMED method will be applied to decrease that long-philosophy and not value-added time to possible minimum level.

\section{LITERATURE REVIEW}

During the project, 20 articles have been reviewed. It has been observed that SMED applications can differ in every facility. SMED was developed by Shigeo Shingo, a Japanese industrial engineer who was extraordinarily successful in reducing the changeover times. Main goal of SMED is to reduce the setup time from hours to less than $10 \mathrm{~min}$.

In SMED, changeover activities are divided as internal activities and external activities. Internal activities are activities which have been done while machine is not working, whereas external activities are activities, which have been done while machine is working. With SMED method, internal activities are tried to be converted to external activities. Then, kaizen is applied to internal and external activities. Also, at 
every step of SMED method, $5 \mathrm{~S}$ is applied. As a final step, process is standardized for operator. Advantages of SMED method are listed as follows (Shingo, 1985; Shingo, 1989; Almomani et al., 2013):

\section{Advantages of SMED}

- Most effective way to optimize changeover process

- Improved machine utilization

- Reduces changeover times

- Elimination of setup errors

- Lower expense for setups

- Lower skill requirements

\section{DATA AND METHODOLOGY}

Production processes of shampoo and hair creams at the factory have been observed and it is decided that the most problematic process is the process of changing colors of the bottles. This process really causes a serious slowness at production. In addition, this process time (setup and cleaning the machine time) adds no value to the product. So, by shortening this time, it will be getting closer to productive system.

\subsection{METHODOLOGY}

SMED method has 7 main steps. These are; separate internal activities from external, standardize external activities, convert internal activities to external, improve internal setup activities, improve external setup activities, automation of activities, complete elimination, respectively. Steps of SMED method led implementation steps of the project. Implementation plan for the project is listed as follows:

1. Observe and analyze set-up time: The video of production line is recorded, multiple activity charts (Time study) are prepared, steps and times of works are determined, Spaghetti Diagram is drawn.

2. Eliminate searching loses: Required equipment for color changeover process are listed, places for equipment are determined with $5 \mathrm{~S}$.

3. Determining internal and external activities: By examining multiple activity charts, the internal activities to be converted to externals are decided.

4. Converting internals to external: How internals can be converted to externals is researched, taking away and bringing equipment, cleaning, data collection, maintenance activities are focused.

5. Kaizen on internal activities: Each internal activity is examined to make them shorter. Methods of positioning, assembly, and disassembly are searched.

6. Kaizen on external activities: Each external activity is examined to make them shorter. Methods of positioning, assembly, and disassembly are searched.

7. Standardization: Reasons of problems are detected and solved, an instruction is prepared, education levels of operators who work on die changeover process are equalized.

\subsection{DATA COLLECTION AND ANALYSIS FOR COLOR CHANGEOVER PROCESS}

It is impossible to observe the entire color changeover processes because combination of all colors equal to 120 combinations. Two color changeover processes (from white to red and from black to yellow) have been observed, a video has been taken and the basic steps of the color changeover process have been determined. Because these two processes have same steps, color changeover process from White to Red is selected and analyzed which took approximately 2 hours. However, other color changeover processes (ie. From Black to White) can last up to 8 hours. Since the total time of 1 shift is equal to $8 \mathrm{hr}$, color changeover process may take almost the whole one shift.

When the production line is analyzed, it is found out that, a machine can produce approximately 18.000 bottles in a shift. Tank which is at the top of the machine provides the plastic color for the bottle. It can be reached to the tank on machine by using upstairs. As the color changeover process starts, the first step is to clean the tank. Operator stops the machine and cleans the inside of the tank by air pressure pipe to make it ready for the new color.

Plastic mixture of old color is poured until the color of the bottles turns to sheer color. Sheer colored bottles are being produced just for cleaning the tank and pipes. Then, these sheer colored bottles are sent to scrap machine for recycling. This is the bottleneck of the process because it takes the longest time. Machine turns the recycled bottles into scrap. Scrap is being used again to produce new bottles. Also, operator empties the scrap material by hand. Operator swipes leftover plastics from the floor and cleans the inside of the machine by hand.

Operator waits until the new color covers the entire bottle. There is a straight white line at the sides of the bottle that is not the same color as the rest of the bottle. This line takes the longest time to transform to new color. While the operator waits for the straight line to turn red, bottles which are produced are being sent to the scrap line for recycling. After the straight line turns into the new color, weight and 
pantone color are controlled. If all the controls fit the criteria, production line is being switched from scrap line to the shampoo filling line. As it is seen the color change over process composes many redundant activities which can be eliminated with some other tools.

\section{FINDINGS}

Implementation plan of SMED have been applied to observed data and solution approaches have been generated.

\subsection{Set-Up Time Observed and Analyzed}

Video recording has been done and multiple activity chart (Time Study) for the process has been analyzed. Also on the multiple activity charts, steps and times of works have been determined.

\subsection{Searching Loses Eliminated}

Places of necessary equipment for the color changeover process have been determined. Necessary equipment will be placed in a wooden shelf to avoid unnecessary walking of the operator.

\subsection{Internal and External Activities Determined}

By examining multiple activity charts, internal and external activities of the color changeover process are defined. Color change over process from white to red includes 78.5 minutes of internal activities and 38.5 minutes of external activities. Approximately, $67 \%$ of total time (117minutes) is performed with internal activities.

\subsection{Converting Internal Activities to External Activities}

One of the main purposes of SMED Method is to ensure capability of activities while the process is running. Therefore, converting internal activities to externals is an important point.

The main reason of the internal activities to take this long is derived from most of the internal activities continue until color of the bottles reach to a sheer color. If the waiting time for removing old color from the machine and turning the color of the plastic mixture to the new color is minimized, completion time of the internal activities will be shorter and also most of the internal activities will be converted to the external activities. Three solution approaches are proposed as the following. Pipes in the machine can be cleaned faster with a chemical solvent mixture, the pipes can be changed with new ones, or another plastic formula can be prepared which is non-sticky to pipes.

\subsubsection{Chemical Mixture: Solvent}

In order to wash out the old color from the pipes that are inside of the machine, a chemical mixture can be poured from top of the machine into the inside of the machine. Chemical mixture can reach to the pipes and clean them.

Solvent of polythene can be produced in a laboratory. This special solvent would have the power to dissolve plastic materials. Solvent of polythene can clean out leftover colored plastic from the pipe in a faster way. By this way, new produced bottles will turn into a sheer color in a shorter time. This will speed up the whole process of changing color.

\subsubsection{Changing the Pipes for New Color}

The machine has 8 pipes inside. These pipes pour the plastic into the die. Therefore plastic gets stacked on the pipes especially on the sides of the bottles. This causes old color to stay on the side of the bottles while rest of the surface of the bottle keeps the new color.

Recommended solution is to change each of the pipes with the clean one as soon as the color raw material depletes in the tank. It takes approximately 15 min to take out the old pipe and assemble the new one.

\subsubsection{New Plastic Raw Material Formula}

Necessity of finding new plastic mixture came up from the current plastic which sticks on the pipe and causes longer color changeover time. In order to prevent plastic from sticking on the pipe, energy of the plastic should be higher than the energy of the surface of the pipe.

In order to decide whether the material is hydrophilic or hydrophobic, the angle between the surface of the pipe and a drop of plastic material should be measured. Hydrophilic materials are substances that make an angle smaller than 90 degrees with the surface and adhere to the surface, whereas hydrophobic materials make an angle greater than 90 degrees with the surface and do not adhere to the surface (Drelich et al., 2011). In the current state, plastic material of the bottle is a hydrophilic material because plastic sticks to the pipe. In order to have hydrophobic plastic material, the energy of the plastic should be between $30-40 \mathrm{~J} / \mathrm{m} 2$. In a special laboratory new non-sticky plastic material can be created.

\subsection{Kaizen on Activities}

On the other side, some Kaizen activities can be suggested to eliminate internal activities.

\subsubsection{Positioning of a new tank}

The new tank can be at the same level with the machine so, the tank can be easy-to-reach for the operator. This kaizen can improve accessibility of the machine and the work safety. 


\subsubsection{Adding color control sensor to machine}

In the current state, machine has ability to control whether the produced bottles have burst or not. This ability is called as pressure check. Color control sensor can be added right by the pressure check. This assignment will cancel out operator's unnecessary activities such as going to check room and re-adjusting color settings on control panel. Also, this assignment will improve quality control of the produced bottles and ensures bottles to match the standard criteria.

\subsubsection{Adding a precision scale on the line}

If the weight of the bottle is lower than the interval, extra shampoo will be filled into the bottle. This would cause loss of shampoo material which would affect the profit. There will be a precision scale assigned on the line. By this way, all of the produced bottles will be under control. Also, there will be no error during the shampoo filling process.

\subsection{Standardization}

\subsubsection{Pre-calculation of the amount of the raw material}

In the current state of the process, firstly operator takes out the pipe from the color bin in order to cut the old color. Then, operator goes to the tank and cleans up the remaining excess old color material and scrap in tank. These leftover materials cause loss of time for the operator and extra bottle production for the machine. This process can be standardized by calculating how much color material and scrap will be needed for the amount of bottles to be produced. By this way, operator will not have the need to clean the tank and efficiency of the machine will increase.

\section{CONCLUSION}

After processes are examined, it has been determined that the biggest problem on the factory is color changing process which is being done at least twice a week. Because of that, studies of this project focused on color changing process in bottle manufacturing. This project applied SMED methodology and applied 7 steps of the SMED. With this research, best solutions are tried to be found to contribute to the factory.

The solution approach of preparing a chemical solvent mixture to clean the pipes is not favored in the factory. Because, it can be harmful for workers health. The second approach, which is changing the pipes for new color, can be applied. Changing each pipe takes 15 minutes. Since there are 8 pipes within the machine, total time will be 120 minutes. This approach can save up to $60 \%$ of time, for the color changeover process which takes longer than $5 \mathrm{hr}$. The third approach, which is preparing another plastic formula (non-sticky to pipes) can also be applied. Although it may be costly initially, this when this formula is prepared, it eliminates the cleaning time of all color change over processes. Since the color change over processes can take from 2 hours to 8 hours, in the average the new plastic non-sticky formula can save $20.5 \%$ of time for any color change over process.

By solving this problem and reducing the loss of time in the process, total production time will be less than normal when producing bottles in different colors. Production planning engineer will be able to change the color of the bottles in a specified standard way. Furthermore, the setup time will be less than what it was used to be. This improvement will be more profitable to the factory and this will affect the company's productivity and efficiency overall.

\section{REFERENCES}

Akerlof, G.A. (1970). The market for lemons: quality uncertainty and the market mechanism. Quarterly Journal of Economics, vol. 84, no. 3, p. $488-500$

Alessandri, T., Cerrato, D., Depperu, D. (2014). Organizational slack, experience and acquisition behavior across varying economic environments. Management Decision, vol. 56, no. 5, p. 967-982.

Almomani, M. A., Aladeemy, M., Abdelhadi, A., Mumani, A. (2013). A proposed approach for setup time reduction through integrating conventional SMED method with multiple criteria decision-making techniques. Computers \& Industrial Engineering, Vol. 66(2), 461-469.

Drelich, J., Chibowski, E., Meng, D. D., Terpilowski, K. (2011). Hydrophilic and superhydrophilic surfaces and materials. Soft Matter, Vol.7(21), 9804-9828.

Shingo, S. (1985). A revolution in manufacturing: the SMED system. Productivity Press, Cambridge, MA.

Shingo, S. (1989). A study of the Toyota production system. Productivity Press, Cambridge, MA. 